\title{
Evaluasi Keberhasilan Studi Mahasiswa Program Sinergi S1-S2 Institut Pertanian Bogor
}

\author{
Imas Fatimah $^{1}$, Eka Intan Kumala Putri ${ }^{2}$, Utami Dyah Safitri ${ }^{3}$ \\ ${ }^{1}$ Sekolah Bisnis-Institut Pertanian Bogor \\ ${ }^{2}$ Fakultas Ekonomi dan Manajemen-Institut Pertanian Bogor \\ ${ }^{3}$ Fakultas Matematika dan Ilmu Pengetahuan Alam-Institut Pertanian Bogor
}

\begin{tabular}{l} 
INFO ARTIKEL \\
\hline Riwayat Artikel: \\
Diterima: $15-02-2020$ \\
Disetujui: $15-07-2020$ \\
\hline Kata kunci: \\
academic achievement; \\
completion of study; \\
fast track program; \\
input characteristics; \\
prestasi akademik; \\
penyelesaian studi; \\
program jalur cepat; \\
karakteristik masukan;
\end{tabular}

\section{Alamat Korespondensi:}

Imas Fatimah

Manajemen Pendidikan Tinggi

Sekolah Bisnis Institut Pertanian Bogor

Jalan Raya Pajajaran Bogor 16151

E-mail: imasf@apps.ipb.ac.id

\begin{abstract}
ABSTRAK
Abstract: This study aims to determine profile of fast track program based on the characteristics input and knowing the factors that influence academic achievement student of fast track program bachelor to master degree IPB. The method used in this study were descriptive analysis and classification and regression tree (CART). This research used primary and secondary data. Primary data were the result of interviews fast track program and secondary data were characteristic input fast track program. The results of the research study show student profile of fast track program dominated by female students, single, study program that have accreditation A, pass an English placement test and self-financing. The CART analysis finds two significant factors associated to student achievement. They were GPA score S1 and selection study program. Other factors are, based on interview result, motivation and commitment of the student in completing the study, type of research, as well as role and commitment of the supervisor in completing the study.
\end{abstract}

\begin{abstract}
Abstrak: Penelitian ini bertujuan menganalisis profil mahasiswa Program Sinergi S1-S2 IPB berdasarkan karakteristik input mahasiswa menggunakan analisis deskriptif. Selanjutnya, menganalisis faktor faktor yang memengaruhi keberhasilan studi mahasiswa menggunakan analisis Classification and Regression Tree (CART) Hasil penelitian menunjukkan bahwa profil mahasiswa Program Sinergi S1-S2 IPB ditinjau dari karakteristik input mahasiswa didominasi oleh mahasiswa perempuan, belum menikah, program studi S2 mempunyai akreditasi A, lulus placement test Bahasa Inggris dan sumber pembiayaan mandiri. Faktor-faktor yang berpengaruh terhadap keberhasilan studi mahasiswa Program Sinergi S1-S2 IPB menggunakan metode CART adalah IPK pendidikan S1 dan pilihan program studi S2. Motivasi dan komitmen mahasiswa dalam menyelesaikan studi, jenis penelitian mahasiswa dan peran dosen pembimbing dalam menyelesaikan studi mahasiswa merupakan faktor lain yang memengaruhi keberhasilan studi mahasiswa dan lulusan Program Sinergi S1-S2 IPB.
\end{abstract}

Peran penting perguruan tinggi sesuai tujuan pendidikan nasional adalah tercapainya kualitas sumberdaya manusia. UndangUndang Nomor 12 tahun 2012 menyebutkan bahwa pengembangan ilmu pengetahuan dan teknologi oleh pendidikan tinggi dapat menghasilkan intelektual, ilmuwan, dan/atau profesional yang berbudaya dan kreatif, toleran, demokratis, berkarakter tangguh serta berani membela kebenaran untuk kepentingan bangsa sehingga daya saing bangsa meningkat menghadapi globalisasi di segala bidang. Oleh karena itu, perguruan tinggi diharapkan dapat meningkatkan kualitasnya. Salah satu standar utama pengukuran kualitas perguruan tinggi adalah mahasiswa dan lulusan (BAN PT, 2011). Lulusan magister (S2) dalam Learning Outcomes (LO) Kerangka Kualifikasi Nasional Indonesia (KKNI) disyaratkan mempunyai IPK $\geq 3.50$ dan masa studi empat semester. Tingkat ketepatan masa studi juga merupakan indikator kualitas perguruan tinggi(Pike \& Graunke, 2015).

Salah satu cara untuk meningkatkan jumlah lulusan program magister dan mempercepat masa studi program magister dalam rangka perkembangan dan pembangunan daerah berkelanjutan, IPB menyelenggarakan Program Sinergi Sarjana Magister (S1-S2). Surat Keputusan Rektor Nomor 8 tahun 2019 menyebutkan bahwa Program Sinergi Sarjana Magister (S1-S2) merupakan program yang mengintegrasikan jenjang sarjana dan jenjang magister sehingga waktu lulus mahasiswa paling sedikit 10 semester dan paling lama 11 semester dengan tetap mengutamakan kualitas tanpa harus lulus terlebih dahulu dari program sarjana. Tujuan adanya program ini agar dapat meningkatkan jumlah lulusan jenjang magister dan dapat mempercepat masa studi karena pada semester tujuh dan delapan jenjang sarjana mahasiswa tersebut dapat mengambil mata kuliah pascasarjana maksimum 18 sks. 
Mahasiswa yang akan mengikuti Program Sinergi Sarjana - Magister harus memiliki kriteria: (1) memiliki IPK $\geq 3.25$ dan telah menyelesaikan paling sedikit 110 SKS selama enam semester; (2) memiliki rekam jejak kematangan individu berdasarkan penilaian pembimbing akademik yang dibuktikan dengan rekomendasi/persetujuan Dosen Pembimbing Akademik/Pembimbing Skripsi dan Ketua Departemen; (3) Program Studi Magister yang diambil berhubungan erat dengan program studi/mayor pada Program Sarjana yang ditempuh; (4) memiliki rencana studi paripurna untuk penyelesaian studi Program Sarjana-Magister yang dipercepat, termasuk rencana riset tesis program magister yang selaras dengan tugas akhir/skripsi Program Sarjana (IPB, 2019).

Penelitian terkait keberhasilan studi mahasiswa pascasarjana sudah banyak dilakukan karena tingkat kegagalan mahasiswa pascasarjana cukup tinggi dan waktu penyelesaian studi yang cukup lama. Topik penelitian mengenai mahasiswa pascasarjana paling sering membahas tingkat putus studi, hubungan dengan dosen pembimbing, kualitas selama pembimbingan, dan isolasi sosial (Jones, 2013). Penelitian yang telah dilakukan untuk mengetahui faktor faktor yang memengaruhi keberhasilan studi berdasarkan karakteristik input mahasiswa yaitu menurut Ramli et al.( 2018), Self Directed Learning Readiness dan prestasi akademik mahasiswa dipengaruhi oleh karakteristik mahasiswa dan faktor internal. Penelitian Yuniar et al. (2019) menjelaskan bahwa faktor utama yang memengaruhi penyelesaian studi mahasiswa magister Sekolah Pascasarjana IPB yaitu (1) kualitas pembimbingan, (2) pelayanan dan lingkungan, (3) kemampuan mahasiswa, (4) motivasi, (5) responsif, (6) pelibatan oleh pembimbing, serta (7) gelar dan prestis. Penelitian lainnya menerangkan bahwa faktor yang memengaruhi keragaman waktu penyelesaian studi mahasiswa program doktor secara umum dapat dikelompokkan menjadi tiga kategori, yaitu (1) faktor kelembagaan atau lingkungan akademik, termasuk bidang studi, lingkungan penelitian, sumber daya dan fasilitas penelitian; (2) kualitas pembimbingan, meliputi frekuensi pertemuan serta dukungan dari rekan-rekan peneliti; (3) karakteristik mahasiswa yaitu jenis kelamin, suku, usia, memiliki anak, status perkawinan, minat terhadap penelitian, dan harapan tentang penelitian (van de Schoot et al., 2013).

Beberapa penelitian sebelumnya tentang pengaruh karakteristik mahasiswa dan latar belakang pendidikan terhadap keberhasilan studi mahasiswa yaitu jenis kelamin (Khwaileh \& Zaza, 2011; Sheard, 2009), status pernikahan (Anindya \& Suhartono, 2012), Usia (Alhajraf \& Alasfour, 2014; Wamala \& Oonyu, 2012), Status akreditasi program studi (Wollast et al., 2018), IPK S1 (Dixon, 2012; Raju \& Schumacker, 2015), pilihan program studi S2 (Groenvynck et al., 2013; Spaulding \& Rockinson-Szapkiw, 2012), kemampuan Bahasa Inggris (Daller \& Phelan, 2015; Green, 2014; Martirosyan, 2015), jaminan keuangan (Crosby, 2011; Millea et al., 2018; Wao \& Onwuegbuzie, 2011), komitmen mahasiswa (Sheard \& Golby, 2007). Selain ditinjau dari karakteristik input mahasiswa dapat dilihat pada tahap perkuliahan dan penyusunan tesis yang memengaruhi keberhasilan studi. Keberhasilan studi ditinjau dari tahap penyusunan tesis yaitu peran dosen pembimbing (Leijen et al., 2016; Miller, 2018) dan lingkungan penelitian (Jiranek, 2010; Pitchforth et al., 2012).

Indikator keberhasilan sudi mahasiswa Program Sinergi S1-S2 mengacu kepada Surat Keputusan Rektor Nomor 8 tahun 2019 yaitu masa studi lulusan Program Sinergi S1-S2 pada jenjang magister paling lama tiga semester. Gambar 1 menyajikan sebaran persentase keberhasilan studi mahasiswa Program Sinergi Sarjana Magister (S1-S2).

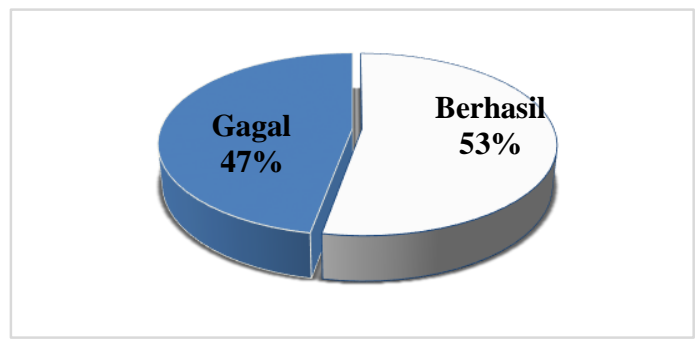

\section{Gambar 1. Sebaran Persentase Keberhasilan Mahasiswa Program Sinergi S1-S2}

Tujuan yang ingin dicapai pada penelitian ini yaitu (1) menganalisis profil mahasiswa Program Sinergi S1-S2 berdasarkan karakteristik input mahasiswa, (2) menganalisis faktor-faktor yang memengaruhi keberhasilan studi mahasiswa Program Sinergi S1-S2 di IPB.

\section{METODE}

Penelitian ini menggunakan data primer dan data sekunder. Data primer diperoleh melalui wawancara mendalam kepada mahasiswa Program Sinergi S1-S2 IPB. Wawancara mendalam merupakan proses mendapatkan keterangan untuk tujuan penelitian dengan memberikan pertanyaan dan sambil bertatap muka antara pewawancara dengan orang yang diwawancarai, dengan atau tanpa menggunakan pedoman wawancara, dimana pewawancara dan informan terlibat dalam kehidupan sosial yang relatif lama(Bungin, 2010). Jenis pertanyaan yang diajukan dalam wawancara dikaitkan dengan pengalaman mahasiswa selama mengikuti pendidikan pascasarjana yang terdiri atas prosedur pendaftaran; kendala selama masa perkuliahan; proses penyusunan tesis, peran dosen pembimbing dalam penyusunan tesis, jaminan pembiayaan dalam penyusunan tesis, lingkungan riset tesis dan publikasi ilmiah hasil riset tesis. 
Teknik sampling untuk data primer menggunakan teknik purposive sampling. Sample yang digunakan merupakan mahasiswa Program Sinergi S1-S2 di IPB yang memiliki waktu studi terlama dan tercepat. Analisis data primer menggunakan analisis deskriptif. Data sekunder berupa data mahasiswa Program Sinergi S1-S2 di IPB tahun masuk 2013 - 2018 sebanyak 478 mahasiswa, laporan tahunan Sekolah Pascasarjana IPB, buku, jurnal dan hasil penelitian lainnya yang mendukung penelitan ini. Analisis data sekunder menggunakan metode korelasi Chi square dan metode Classification and Regression Tree (CART). Analisis korelasi Chi-Square bertujuan untuk menguji pengaruh dua variabel yang memunyai skala nominal atau ordinal. CART merupakan metode statistik non-parametrik yang dapat digunakan untuk melihat hubungan antara peubah respon dan peubah penjelas secara eksploratif (Breiman et al., 1984) Menurut Lewis (2000), karena CART merupakan metode nonparametrik, maka CART tidak ada asumsi yang diperlukan terkait dengan peubah penjelasnya. CART dapat menangani peubah penjelas numerik yang menjulur kanan ataupun kiri serta menangani peubah penjelas kategorik nominal maupun ordinal. Hal tersebut merupakan suatu keunggulan karena dapat mempermudah peneliti dalam praproses data. CART menampilkan hasil akhir berupa struktur pohon dengan penyekat simpul peubah respons yang berjenis kontinu maupun kategorik. Analisis dengan peubah respons kategorik menghasilkan pohon klasifikasi, sedangkan analisis dengan peubah respon numerik menghasilkan pohon regresi. Peubah yang digunakan dalam analisis CART adalah peubah penjelas (X) merupakan karakteristik input mahasiswa dan peubah respon (Y) merupakan keberhasilan studi mahasiswa Program Sinergi S1-S2. Tabel 1 menjelaskan karakteristik input yang digunakan dalam penelitian ini.

Tabel 1. Karakteristik Input Mahasiswa

\begin{tabular}{|c|c|c|c|c|c|c|}
\hline Peubah & Keterangan Peubah & \multicolumn{5}{|c|}{ Kategori } \\
\hline $\mathrm{X} 1$ & Jenis kelamin & \multicolumn{5}{|c|}{$\begin{array}{l}1=\text { laki-laki } \\
2=\text { perempuan }\end{array}$} \\
\hline $\mathrm{X} 2$ & Status pernikahan saat diterima & \multicolumn{5}{|c|}{$\begin{array}{l}1=\text { belum kawin } \\
2=\text { sudah kawin }\end{array}$} \\
\hline X3 & Usia saat diterima & \multirow{2}{*}{\multicolumn{5}{|c|}{$\begin{array}{l}1=A \\
2=B \\
3=C\end{array}$}} \\
\hline $\mathrm{X} 4$ & Status akreditasi program studi S2 & & & & & \\
\hline $\mathrm{X} 5$ & IPK S1 & & & & & \\
\hline X6 & Pilihan program studi S2 & $\begin{array}{l}1=\mathrm{ARL} \\
2=\mathrm{ENT} \\
3=\mathrm{FIT} \\
4=\mathrm{ITB} \\
5=\mathrm{PBT} \\
6=\mathrm{AKU} \\
7=\mathrm{SDP}\end{array}$ & $\begin{array}{l}8=\mathrm{SPL} \\
9=\mathrm{INP} \\
10=\mathrm{ITP} \\
11=\mathrm{KVT} \\
12=\mathrm{MEJ} \\
13=\mathrm{SVK} \\
14=\mathrm{THH}\end{array}$ & $\begin{array}{l}15=\mathrm{IPN} \\
16=\mathrm{SIL} \\
17=\mathrm{TMP} \\
18=\mathrm{TPP} \\
19=\mathrm{BIK} \\
20=\mathrm{BOT} \\
21=\mathrm{BSH}\end{array}$ & $\begin{array}{l}22=\mathrm{FIS} \\
23=\mathrm{KIM} \\
24=\mathrm{KOM} \\
25=\mathrm{MAT} \\
26=\mathrm{MIK} \\
27=\mathrm{STK} \\
28=\mathrm{AGB}\end{array}$ & $\begin{array}{l}29=\mathrm{EKO} \\
30=\mathrm{EPN} \\
31=\mathrm{ESL} \\
32=\mathrm{ESK} \\
33=\mathrm{MAN} \\
34=\mathrm{IKA}\end{array}$ \\
\hline $\mathrm{X} 7$ & Placement test Bahasa Inggris & \multicolumn{5}{|c|}{$\begin{array}{l}1=\text { Lulus } \\
2=\text { Tidak lulus }\end{array}$} \\
\hline $\mathrm{X} 8$ & Sumber biaya pendidikan & \multicolumn{5}{|c|}{$\begin{array}{l}1=\text { beasiswa } \\
2=\text { mandiri }\end{array}$} \\
\hline $\mathrm{Y}$ & Keberhasilan Program Sinergi & \multicolumn{5}{|c|}{$\begin{array}{l}1=\text { Berhasil (lulus } \leq 3 \text { semester) } \\
2=\text { Gagal }(\text { Lulus }>3 \text { semester/DO/MD) }\end{array}$} \\
\hline
\end{tabular}

\section{HASIL}

\section{Profil Mahasiswa Program Sinergi S1-S2 IPB Ditinjau dari Karakteristik Input Mahasiswa dan} Tahapan Masa Penyelesaian Studi

Jumlah mahasiswa Program Sinergi S1 S2 IPB tahun 2013 sampai dengan tahun 2018 berjumlah 478 mahasiswa. Jumlah mahasiswa yang sudah lulus (84\%), jumlah mahasiswa yang masih aktif (11\%) dan jumlah mahasiswa yang tidak menyelesaikan jenjang S2 (5\%) sebagaimana ditunjukkan pada gambar 2.

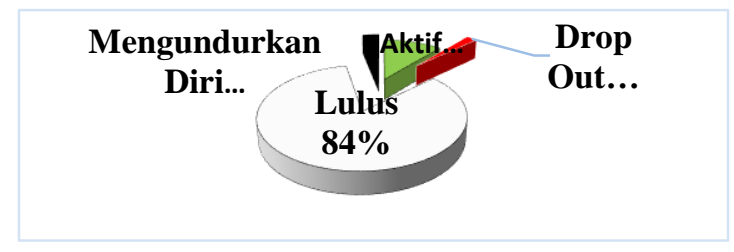

Gambar 2. Sebaran Mahasiswa Program Sinergi S1-S2 
Profil mahasiswa Program Sinergi S1-S2 IPB berdasarkan karakteristik input mahasiswa pada gambar 3a menunjukkan persentase mahasiswa perempuan (75\%) lebih besar dibandingkan mahasiswa laki-laki (25\%). Dilihat dari status pernikahan, persentase mahasiswa Program Sinergi S1 - S2 IPB dengan status sudah menikah sebesar 20\%, sedangkan persentase mahasiswa yang belum menikah sebesar $80 \%$ (Gambar 3b). Sebaran peubah akreditasi program studi A sebesar 96\%, akreditasi program studi B sebesar 3\% dan akreditasi C sebesar 1\% (Gambar 3c). Mahasiswa yang mempunyai sumber biaya pendidikan dari beasiswa sebesar 28\% lebih sedikit dibandingkan dengan yang tidak mendapatkan beasiswa yaitu 72\% (Gambar 3d), hal ini dikarenakan beasiswa untuk program ini hanya ada pada tahun 2013 dan 2014. Hasil placement test Bahasa Inggris menunjukkan persentase mahasiswa yang lulus tes sebesar $72 \%$ dan yang tidak lulus sebesar $28 \%$ (Gambar 3e).

(a)

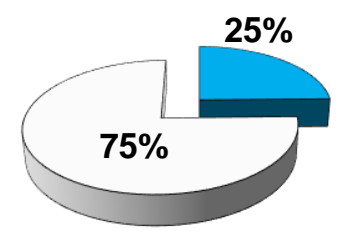

口Laki - Laki 口Perempuan (b)

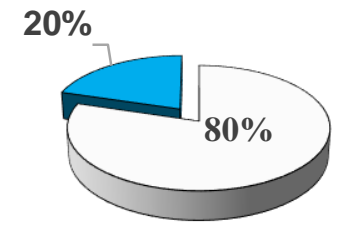

$\square$ Belum Menikah $\square$ Menikah (c)

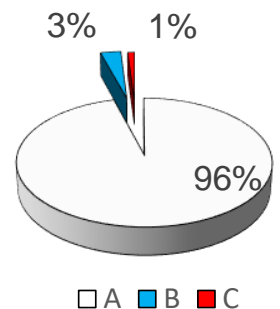

(d)

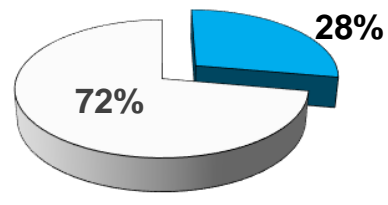

$\square$ Beasiswa $\square$ Mandiri (e)

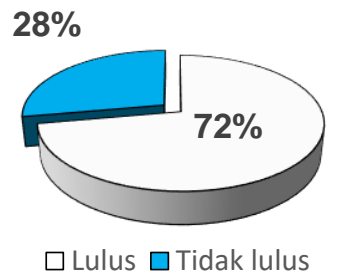

\section{Gambar 3. Sebaran (a) Jenis Kelamin, (b) Status Pernikahan, (c) Akreditasi Program Studi, (d) Sumber Pembiayaan dan (e) Placement Test Bahasa Inggris}

Karakteristik input mahasiswa yaitu jenis kelamin, status pernikahan, akreditasi program studi jenjang S1 dan pilihan program studi jenjang S2 merupakan peubah peubah dengan skala kategorik ditabulasi silang dengan kategori keberhasilan studi mahasiswa dapat dilihat pada tabel 2. Uji Chi square antara karakteristik input mahasiswa terhadap keberhasilan studi menunjukkan peubah-peubah status pernikahan, IPK jenjang S1, pilihan program studi S2 dan sumber biaya pendidikan signifikan pada taraf nyata $5 \%$.

Tabel 2. Sebaran Karakteristik Input Mahasiswa Terhadap Keberhasilan Studi

\begin{tabular}{|c|c|c|c|c|c|c|c|}
\hline \multirow[t]{2}{*}{ Peubah } & \multirow[t]{2}{*}{ Kategori } & \multicolumn{2}{|c|}{ Berhasil } & \multicolumn{2}{|c|}{ Gagal } & \multirow[t]{2}{*}{ Jumlah } & P-value Chi square \\
\hline & & $\Sigma$ & $\%$ & $\Sigma$ & $\%$ & & \\
\hline \multirow{2}{*}{ Jenis Kelamin } & Laki-laki & 57 & 48 & 61 & 52 & 118 & 0.246 \\
\hline & Perempuan & 196 & 54 & 164 & 46 & 360 & \\
\hline \multirow{2}{*}{ Status Pernikahan } & Belum menikah & 212 & 56 & 169 & 44 & 381 & $0.018^{*}$ \\
\hline & Menikah & 41 & 42 & 56 & 58 & 97 & \\
\hline \multirow{2}{*}{ Usia } & Usia $<23$ tahun & 240 & 54 & 208 & 46 & 448 & 0.277 \\
\hline & Usia $\geq 23$ tahun & 13 & 43 & 17 & 57 & 30 & \\
\hline \multirow{3}{*}{ Akreditasi Program Studi } & A & 241 & 53 & 217 & 47 & 458 & 0.475 \\
\hline & $\mathrm{B}$ & 8 & 53 & 7 & 47 & 15 & \\
\hline & $\mathrm{C}$ & 4 & 80 & 1 & 20 & 5 & \\
\hline \multirow[b]{2}{*}{ IPK S1 } & IPK $S 1<3.5$ & 67 & 45 & 83 & 55 & 150 & $0.014^{*}$ \\
\hline & IPK $\mathrm{S} 1 \geq 3.5$ & 186 & 57 & 142 & 43 & 328 & \\
\hline \multirow{5}{*}{ Pilihan Program Studi } & ARL & 2 & 33 & 4 & 67 & 6 & $0.000^{*}$ \\
\hline & ENT & 2 & 100 & & & \multicolumn{2}{|c|}{$0 \quad 2$} \\
\hline & FIT & & 0 & 1 & & 100 & 1 \\
\hline & ITB & & 0 & 6 & & 100 & 6 \\
\hline & PBT & 2 & 15 & 11 & & 85 & 13 \\
\hline
\end{tabular}


Tabel 2. Sebaran Karakteristik Input Mahasiswa Terhadap Keberhasilan Studi (Lanjutan)

\begin{tabular}{|c|c|c|c|c|c|c|c|}
\hline & AKU & 4 & 36 & 7 & 64 & 11 & \\
\hline & SDP & 8 & 67 & 4 & 33 & 12 & \\
\hline & SPL & 11 & 65 & 6 & 35 & 17 & \\
\hline & INP & 14 & 54 & 12 & 46 & 26 & \\
\hline & ITP & 10 & 91 & 1 & 9.1 & 11 & \\
\hline & KVT & 7 & 23 & 23 & 77 & 30 & \\
\hline & MEJ & 4 & 24 & 13 & 76 & 17 & \\
\hline & SVK & 16 & 47 & 18 & 53 & 34 & \\
\hline & THH & 6 & 60 & 4 & 40 & 10 & \\
\hline & IPN & 7 & 64 & 4 & 36 & 11 & \\
\hline & SIL & 4 & 80 & 1 & 20 & 5 & \\
\hline & TMP & 6 & 46 & 7 & 54 & 13 & \\
\hline & TPP & 2 & 100 & & 0 & 2 & \\
\hline & BIK & 7 & 100 & & 0 & 7 & \\
\hline & BOT & & 0 & 1 & 100 & 1 & \\
\hline & BSH & 6 & 100 & & 0 & 6 & \\
\hline & FIS & 6 & 60 & 4 & 40 & 10 & \\
\hline & KIM & 5 & 56 & 4 & 44 & 9 & \\
\hline & KOM & 5 & 36 & 9 & 64 & 14 & \\
\hline & MAT & 19 & 79 & 5 & 21 & 24 & \\
\hline & MIK & 7 & 64 & 4 & 36 & 11 & \\
\hline & STK & 3 & 100 & & 0 & 3 & \\
\hline & AGB & 44 & 70 & 19 & 30 & 63 & \\
\hline & EKO & 28 & 41 & 40 & 59 & 68 & \\
\hline & EPN & 2 & 40 & 3 & 60 & 5 & \\
\hline \multirow[t]{2}{*}{ Nilai placement test Bahasa Inggris } & Lulus & 185 & 54 & 160 & 46 & 345 & 0.624 \\
\hline & Tidak lulus & 68 & 51 & 65 & 49 & 133 & \\
\hline \multirow[t]{2}{*}{ Sumber biaya pendidikan } & Beasiswa & 59 & 44 & 74 & 56 & 133 & $0.02 *$ \\
\hline & Mandiri & 194 & 56 & 151 & 44 & 345 & \\
\hline
\end{tabular}

Faktor Faktor yang Memengaruhi Keberhasilan Studi Mahasiswa Program Sinergi Sarjana-Magister (S1-S2) IPB

Keberhasilan studi mahasiswa Program Sinergi S1-S2 menggunakan dua kriteria yaitu berhasil jika mahasiswa lulus dengan masa studi kurang dari sama dengan tiga semester dan gagal jika mahasiswa lulus dengan masa studi lebih dari tiga semester atau mahasiswa yang tidak menyelesaikan studi jenjang magister. Program Sinergi S1-S2 berdasarkan kriteria tersebut menghasilkan tujuh simpul dengan empat simpul terminal. Peubah pertama yang menjadi penyekat adalah IPK S1 dan peubah kedua adalah pilihan program studi sebagaimana ditunjukkan pada gambar 4.

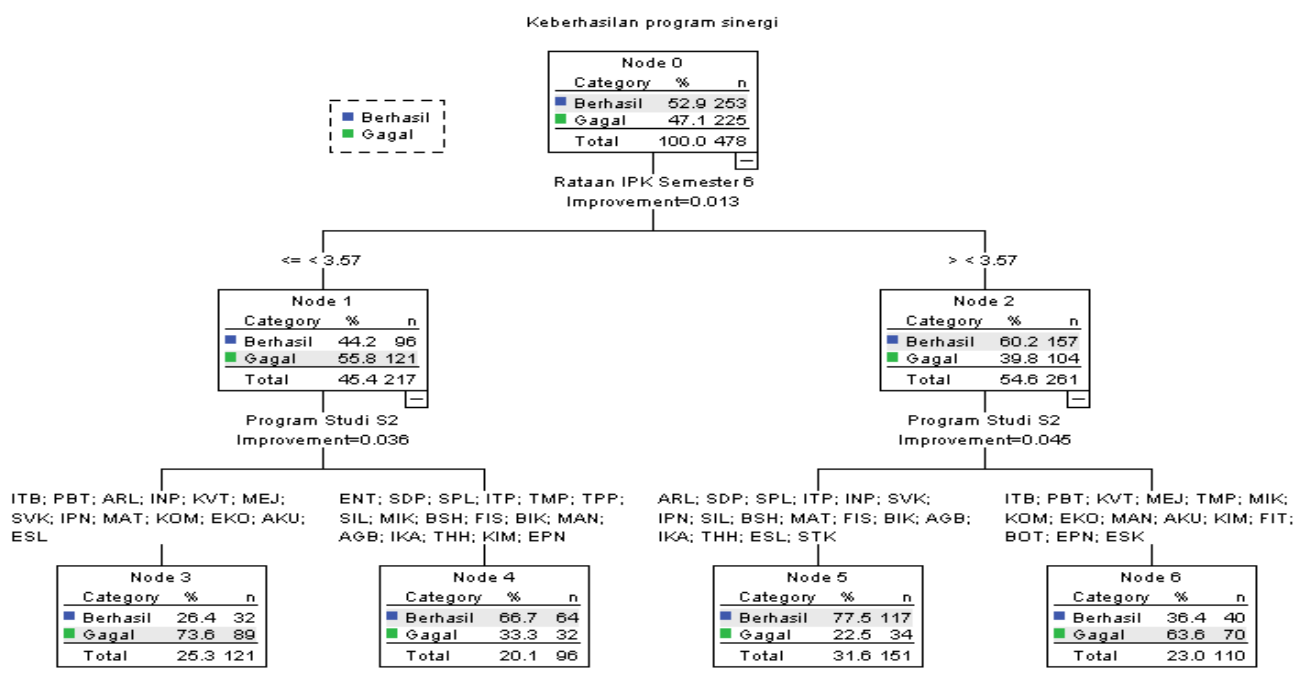

Gambar 4. Pohon Klasifikasi Keberhasilan Program Sinergi S1-S2 


\section{PEMBAHASAN \\ Profil Mahasiswa Program Sinergi S1-S2 IPB Ditinjau dari Karakteristik Input Mahasiswa dan Tahapan Masa Penyelesaian Studi}

Berdasarkan hasil analisis deskriptif untuk melihat profil mahasiswa Program Sinergi S1-S2 ditinjau dari karakteristik input mahasiswa menunjukkan bahwa persentase kategori tidak merata pada setiap karakteristik input mahasiswa. Kategori mahasiswa Program Sinergi S1-S2 terbanyak ditunjukkan pada jenis kelamin perempuan, status pernikahan belum menikah, akreditasi program studi A pada jenjang pendidikan S1, sumber pembiayaan mandiri dan lulus placement test Bahasa Inggris. Tabel 2 menunjukkan bahwa persentase keberhasilan studi yang tinggi diraih oleh mahasiswa perempuan, mahasiswa yang belum menikah, mahasiswa program studi yang mempunyai akreditasi $\mathrm{C}$ dan mahasiswa yang lulus placement test Bahasa Inggris. Hal yang menarik dari tabulasi silang antara peubah penjelas dengan keberhasilan studi mahasiswa, persentase kelulusan mahasiswa yang berasal program studi dengan akreditasi C (80\%) lebih besar daripada mahasiswa yang berasal dari program studi dengan akreditasi A dan akreditasi B (53\%). Kondisi ini menunjukkan bahwa lulusan program studi dengan akreditasi A dan akreditasi B belum memberikan tingkat keberhasilan studi mahasiswa yang nyata.

Karakteristik input mahasiswa merupakan peubah-peubah dengan skala kategorik ditabulasi silang dengan kategori keberhasilan studi mahasiswa dapat dilihat pada tabel 2. Uji Chi square antara karakteristik input mahasiswa terhadap keberhasilan studi menunjukkan adanya hubungan antara peubah-peubah status pernikahan, IPK jenjang S1, pilihan program studi S2 dan sumber biaya pendidikan dengan keberhasilan studi pada taraf nyata.

\section{Faktor-Faktor yang Memengaruhi Keberhasilan Studi Mahasiswa Program Sinergi Sarjana-Magister (S1-S2) IPB}

Berdasarkan hasil pohon klasifikasi, peubah pertama yang menjadi penyekat adalah IPK S1 (semester 6). IPK S1 merupakan peubah penjelas yang paling berpengaruh terhadap keberhasilan studi mahasiswa Program Sinergi S1-S2. Hal ini serupa dengan temuan Kamal (2011), (Dixon (2012), Dixon (2012) dan Siregar (2015). Mahasiswa yang memiliki IPK S1 $\leqslant$ 3.57 memiliki persentase kegagalan lebih tinggi (55.8\%) dibandingkan dengan mahasiswa yang memiliki IPK S1>3.57 (39.8\%). Peubah kedua yang menjadi penyekat adalah program studi. Hal ini sejalan dengan hasil penelitian Basith et al. (2020), Spaulding \& Rockinson-Szapkiw (2012) dan Groenvynck et al. (2013). Peubah ini menyekat mahasiswa yang mempunyai IPK S1 $\leqslant 3.57$ dan IPK S1 > 3.57. Pilihan program studi pada simpul kiri yang menyekat mahasiswa dengan IPK S1 $\leqslant 3.57$ adalah program studi ITB, PBT, ARL, INP, KVT, MEJ, SVK, IPN, MAT, KOM, EKO, AKU dan ESL. Simpul kanan adalah program studi ENT, SDP, SPL, ITP, TMP, TPP, SIL, MIK, BSH, FIS, BIK, MAN, AGB, IKA, THH, KIM dan EPN. Persentase kegagalan mahasiswa pada simpul kiri lebih besar, yaitu sebesar $73.6 \%$ sementara pada simpul kanan sebesar $33.3 \%$. Sementara itu, pilihan program studi pada simpul kiri yang menyekat mahasiswa dengan IPK S1>3.57 adalah program studi ARL, SDP, SPL, ITP, INP, SVK, IPN, SIL, BSH, MAT, FIS, BIK, AGB, IKA, THH, ESL dan STK. Simpul kanan adalah program studi ITB, PBT, KVT, MEJ, TMP, MIK, KOM, EKO, MAN, AKU, KIM, FIT, BOT, EPN dan ESK. Persentase kegagalan mahasiswa pada simpul kanan lebih besar sebesar $63.6 \%$ sementara pada simpul kiri sebesar $22.5 \%$. Kelas I memiliki persentase kegagalan tertinggi pada keberhasilan studi mahasiswa Program Sinergi S1-S2 sebagaimana ditunjukkan pada tabel 3.

Tabel 3. Klasifikasi Keberhasilan Studi Mahasiswa Program Sinergi S1-S2

\begin{tabular}{|c|c|c|c|c|}
\hline Kelas & $\mathbf{N}$ & Keberhasilan (\%) & Kegagalan (\%) & Peubah Penciri \\
\hline 1 & 121 & 26.4 & 73.6 & $\begin{array}{l}\text { Memiliki IPK S1 } \leqslant 3.57 \text { dan pilihan program studi S2 adalah program } \\
\text { studi ITB, PBT, ARL, INP, KVT, MEJ, SVK, IPN, MAT, KOM, EKO, } \\
\text { AKU dan ESL }\end{array}$ \\
\hline 2 & 96 & 66.7 & 33.3 & $\begin{array}{l}\text { Memiliki IPK } \mathrm{S} 1 \leqslant 3.57 \text { dan pilihan program studi S2 adalah program } \\
\text { ENT, SDP, SPL, ITP, TMP, TPP, SIL, MIK, BSH, FIS, BIK, MAN, } \\
\text { AGB, IKA, THH, KIM dan EPN }\end{array}$ \\
\hline 3 & 151 & 77.5 & 22.5 & $\begin{array}{l}\text { Memiliki IPK S1 > } 3.57 \text { dan pilihan program studi S2 adalah program } \\
\text { studi ARL, SDP, SPL, ITP, INP, SVK, IPN, SIL, BSH, MAT, FIS, BIK, } \\
\text { AGB, IKA, THH, ESL dan STK }\end{array}$ \\
\hline 4 & 110 & 36.4 & 63.6 & $\begin{array}{l}\text { Memiliki S1 > } 3.57 \text { dan pilihan program studi S2 adalah program studi } \\
\text { ITB, PBT, KVT, MEJ, TMP, MIK, KOM, EKO, MAN, AKU, KIM, FIT, } \\
\text { BOT, EPN dan ESK }\end{array}$ \\
\hline
\end{tabular}

Wawancara kepada lulusan mahasiswa yang memiliki masa studi tercepat dan terlama pada kelompok lulusan mahasiswa Program Sinergi S1-S2 berdasarkan hasil analisis metode CART pada tabel 2. Pertanyaan yang diajukan merupakan pertanyaan yang terkait dengan prosedur pendaftaran, kendala selama perkuliahan, proses penyusunan tesis. Pertanyaan yang terkait proses penyusunan tesis yaitu peran dosen pembimbing, jaminan keuangan, lingkungan penelitian dan publikasi ilmiah. 
Lulusan mahasiswa dengan masa studi tercepat pada setiap kelompok menyajikan fakta bahwa ketika proses pendaftaran mahasiswa sudah mempunyai rencana penelitian tesis dengan topik penelitian magister melanjutkan topik penelitian sarjana dan pelaksanaannya tidak ada kendala sesuai dengan perencanaan penelitian. Dosen pembimbing berperan sekali dalam penyelesaian studi mahasiswa yaitu dalam memantau kemajuan studinya dan komunikasi antara mahasiswa dengan dosen pembimbing lancar. Lingkungan penelitian mendukung proses penyelesaian penelitian seperti fasilitas penelitian sudah memadai. Selain itu, lulusan tersebut tidak mempunyai kendala dalam pembiayaan studinya dan proses publikasi ilmiah. Faktor lain yang paling utama yang disampaikan mahasiswa adalah komitmen dan motivasi mahasiswa dalam menyelesaikan studi.

Fakta yang ditemukan pada lulusan dengan masa studi terlama pada setiap kelompok adalah pelaksanaan penelitian tesis tidak sesuai dengan perencanaan penelitian, pada umumnya menemui hambatan dalam proses penelitian yang terkait dengan jenis dan lokasi penelitian. Selain itu, motivasi dan komitmen dalam menyelesaikan studi pada lulusan ini kurang karena lulusan ini sambil bekerja sehingga kurang fokus dalam menyusun tesis sehingga menghambat penyelesaian studinya. Meskipun pada umumnya lulusan tersebut mempunyai dosen pembimbing, lingkungan penelitian yang mendukung dalam penyelesaian studi, tidak mempunyai kendala dalam pembiayaan studi dan proses publikasi ilmiah.

Faktor lain yang memengaruhi keberhasilan studi mahasiswa dan tidak terdapat dalam hasil analisis CART berdasarkan hasil wawancara kepada mahasiswa adalah motivasi dan komitmen mahasiswa dalam menyelesaikan studi, jenis penelitian mahasiswa dan peran dosen pembimbing dalam menyelesaikan studi mahasiswa. Hal tersebut sesuai dengan hasil penelitian Sheard \& Golby, (2007), Miller (2018) dan Pitchforth et al (2012).

\section{Implikasi Manajerial}

Hasil penelitian berdasarkan metode CART menunjukkan bahwa persentase keberhasilan mahasiswa Program Sinergi S1-S2 yang paling kecil pada kelas I ditunjukkan pada tabel 3. Dengan mempertimbangkan karakteristik keberhasilan studi mahasiswa pada kelas tersebut, pelaksanaan proses seleksi mahasiswa Program Sinergi S1-S2 pada program studi ITB, PBT, ARL, INP, KVT, MEJ, SVK, IPN, MAT, KOM, EKO, AKU dan ESL sebaiknya lebih memperhatikan calon pelamar yang memiliki ciri-ciri IPK S1 kurang dari atau sama dengan 3.57. Penggunaan kriteria ini, ketika kondisi jumlah calon mahsiswa pada program studi tertentu telah melebihi kuota yang telah ditetapkan sehingga harus dipilih calon mahasiswa yang terbaik.

Faktor lain yang tidak terdapat dalam model berdasarkan hasil wawancara kepada mahasiswa adalah motivasi dan komitmen mahasiswa dalam menyelesaikan studi, jenis penelitian mahasiswa dan peran/komitmen dosen pembimbing dalam menyelesaikan studi mahasiswa. Berdasarkan hasil penelitian tersebut, untuk mencapai keberhasilan studi mahasiswa Program Sinergi S1-S2 harus dilakukan peningkatan kualitas input mahasiswa, peningkatan kualitas proses perkuliahan, dan peningkatan kualitas proses penyusunan tesis. Berikut langkah-langkah yang dapat direkomendasikan dalam menunjang keberhasilan studi mahasiswa. Pertama, peningkatan kualitas input mahasiswa yaitu proses seleksi calon mahasiswa baru lebih mengutamakan kriteria IPK pendidikan jenjang S1 dan mahasiswa yang mempunyai komitmen yang tinggi dalam menyelesaikan studi. Kedua, peningkatan kualitas proses perkuliahan dan peningkatan proses penyusunan studi yaitu (1) menciptakan lingkungan akademik yang kondusif sehingga dapat menumbuhkan motivasi dan komitmen mahasiswa untuk berkonsentrasi dalam menyelesaikan studi, (2) jenis penelitian yang dilaksanakan oleh mahasiswa tidak memerlukan waktu lama dengan tidak mengurangi kualitas penelitian tersebut, dan (3) dosen pembimbing berkomitmen dalam keberhasilan studi mahasiswa dengan cara memberikan arahan, bimbingan dan memantau kemajuan studi mahasiswanya dengan lebih maksimal.

\section{SIMPULAN}

Profil mahasiswa Program Sinergi S1-S2 IPB ditinjau dari karakteristik input mahasiswa didominasi oleh mahasiswa perempuan, belum menikah, program studi mempunyai akreditasi A, lulus placement test Bahasa Inggris dan sumber pembiayaan mandiri. Faktor-faktor yang berpengaruh terhadap keberhasilan studi mahasiswa Program Sinergi S1-S2 IPB menggunakan metode CART adalah IPK pendidikan S1 dan pilihan program studi S2. Motivasi dan komitmen mahasiswa dalam menyelesaikan studi, jenis penelitian mahasiswa dan peran/komitmen dosen pembimbing dalam meyelesaikan studi mahasiswa merupakan faktor lain yang memengaruhi keberhasilan studi mahasiswa dan lulusan Program Sinergi S1 -S2 IPB.

Upaya peningkatan keberhasilan studi mahasiswa Program Sinergi S1-S2 dapat dilakukan dengan meningkatkan kualitas input mahasiswa, kualitas proses perkuliahan dan kualitas proses penyusunan tesis. Oleh karena itu, diperlukan koordinasi antara mahasiswa, dosen, pengelola program studi dan pengelola Pascasarjana. Perlu dilakukan penelitian lanjutan dengan menambah peubah bebas yaitu kurikulum dan kondisi fisik mahasiswa. Indikator keberhasilan studi mahasiswa lainnya adalah waktu tunggu lulusan Program Sinergi S1-S2 dalam mendapatkan pekerjaan.

\section{UCAPAN TERIMA KASIH}

Terima kasih disampaikan kepada Kementerian Riset, Teknologi dann Pendidikan Tinggi dan Kementerian Pendidikan dan Kebudayaan yang telah memberikan Beasiswa Tenaga Kependidikan Berprestasi (PaSTi) bagi tenaga kependidikan di perguruan tinggi. 


\section{DAFTAR RUJUKAN}

Alhajraf, N. M., \& Alasfour, A. M. (2014). The Impact of Demographic and Academic Characteristics on Academic Performance. International Business Research, 7(4), 92-100. https://doi.org/10.5539/ibr.v7n4p92

BAN PT. (2011). Akreditasi Institusi Perguruan Tinggi - Buku III Pedoman Penyusunan Borang. BAN PT.

Basith, A., Syahputra, A., \& Aris Ichwanto, M. (2020). Academic Self-Efficacy As Predictor of Academic Achievement. JPI (Jurnal Pendidikan Indonesia), 9(1), 163. https://doi.org/10.23887/jpi-undiksha.v9i1.24403

Breiman, L., Freidman, J. H., Olshen, R. A., \& Stone, C. J. (1984). Classification and Regression Tree.

Bungin, B. (2010). Metode Penelitian Kualitatif. Rajawali Pers.

Crosby, H. (2011). Exploring Achievement : Factors A ffecting Native A merican College Student Success By: Heather Crosby An Applied Research Project ( Political Science 5397 ) Submitted to the Department of Political Science Texas State University In Partial Fulfillm.

Daller, M., \& Phelan, D. (2015). Michael H Daller and David Phelan Predicting International Student Study Success. Applied Linguistics Review, January 2013.

Dixon, D. (2012). Prediction of Osteopathic Medical School Performance. Journal of Americal Osteopathic Association, 112(4), 175-181. https://doi.org/112/4/175 [pii]

Green, J. A. (2014). The Effect of English Proficiency and Ethnicity on Academic Performance and Progress. Advances in Health Sciences Education, 20(1), 219-228. https://doi.org/10.1007/s10459-014-9523-7

Groenvynck, H., Vandevelde, K., \& Van Rossem, R. (2013). The PhD track: Who succeeds, who drops out? Research Evaluation, 22(4), 199-209. https://doi.org/10.1093/reseval/rvt010

Hadi, W. A., \& Suhartono. (2012). Pemodelan Faktor-faktor yang Memengaruhi Prestasi Mahasiswa Pascasarjana ITS dengan Regresi Logistik dan Neural Network. Jurnal Sains dan Seni ITS, 1(1).

Jiranek, V. (2010). Potential Predictors of Timely Completion Among Dissertation Research Students at an Australian Faculty of sciences. International Journal of Doctoral Studies, 5, 1-13. https://doi.org/10.28945/709

Jones, M. (2013). Issues in Doctoral Studies - Forty Years of Journal Discussion : Where have we been and where are we going ? International Journal of Doctoral Studies, 8.

Kamal, M. (2011). Metode CHAID dan Korespondensi untuk Menentukan Faktor - Faktor yang Berasosiasi dengan Keberhasilan Studi Mahasiswa.

Khwaileh, F., \& Zaza, H. (2011). Gender Differences in Academic Performance among Undergraduates at the University of Jordan: Are They Real or Stereotyping? College Student Journal, 45(3), 633.

Leijen, Lepp, L., \& Remmik, M. (2016). Why did I Drop Out? Former Students' Recollections about Their Study Process and Factors Related to Leaving the Doctoral Studies. Studies in Continuing Education, 38(2), 129-144. https://doi.org/10.1080/0158037X.2015.1055463

Lewis, R. (2000). An Introduction to Classification and Regression.

Martirosyan, N. M. (2015). Impact of English Proficiency on Academic Performance of International Students. 5(1), 60-71.

Millea, M., Wills, R., Elder, A., \& Molina, D. (2018). What Matters in College Student Success? Determinants of College Retention and Graduation Rates. Education, 138(4), 309-322.

Peraturan Rektor IPB nomor 8/IT3/PP/2019 tentang Pedoman Penyelenggaraan Program Sinergi Sarjana Magister (S1 -S2) Institut Pertanian Bogor (2019).Miller, M. (2018). Graduation 101: Critical Strategies for African American Men College Completion. Education, 138(4), 301-308.

Pike, G. R., \& Graunke, S. S. (2015). Examining the Effects of Institutional and Cohort Characteristics on Retention Rates. Research in Higher Education, 56(2), 146-165. https://doi.org/10.1007/s11162-014-9360-9

Pitchforth, J., Beames, S., Thomas, A., Falk, M., Farr, C., Gasson, S., Thamrin, S. A., \& Mengersen, K. (2012). Factors affecting timely completion of a PhD: A complex systems approach. Journal of the Scholarship of Teaching and Learning, 12(4), 124-135. http://www.eric.ed.gov/ERICWebPortal/detail?accno=EJ992131

Raju, D., \& Schumacker, R. (2015). Exploring Student Characteristics of Retention That Lead To Graduation in. Journal of College Student Retention: Research, Theory \& Practice, 16(4), 563-591. https://doi.org/10.2190/CS.16.4.e

Ramli, N., Muljono, P., \& Afendi, M. F. (2018). Faktor-Faktor yang Berpengaruh terhadap Self Directed Learning Readiness Dan Prestasi Akademik. Jurnal Kependidikan, 2(1), 153-166. https://doi.org/https://doi.org/10.21831/jk.v2i1

Sheard, M. (2009). Hardiness Commitment, Gender, and Age Differentiate University Academic Performance. British Journal of Educational Psychology, 79(1), 189-204. https://doi.org/10.1348/000709908X304406

Sheard, M., \& Golby, J. (2007). Hardiness and Undergraduate Academic Study: The Moderating Role of Commitment. Personality and Individual Differences, 43(3), 579-588. https://doi.org/10.1016/j.paid.2007.01.006

Siregar, F. (2015). Kajian Waktu Penyelesaian Studi Mahasiswa Sekolah Pascasarjana IPB dan Implikasi Manajerialnya. Tesis tidak diterbitkan. Sekolah Bisnis-Institut Pertanian Bogor.

Spaulding, L. S., \& Rockinson-Szapkiw, A. J. (2012). Hearing Their Voices: Factors Doctoral Candidates Attribute to Their Persistence. International Journal of Doctoral Studies, 7, 199-219. https://doi.org/10.28945/1589

van de Schoot, R., Yerkes, M. A., Mouw, J. M., \& Sonneveld, H. (2013). What Took Them So Long? Explaining PhD Delays among Doctoral Candidates. PLoS ONE, 8(7). https://doi.org/10.1371/journal.pone.0068839 
Wamala, R., \& Oonyu, J. C. (2012). Completion Time Dynamics for Masters and Doctoral Studies at Makerere University. Contemporary Issues in Education Research (CIER), 5(2), 131. https://doi.org/10.19030/cier.v5i2.6946

Wao, H. O., \& Onwuegbuzie, A. J. (2011). A Mixed Research Investigation of Factors Related to Time to the Doctorate in Education. International Journal of Doctoral Studies, 6, 115-134. https://doi.org/10.28945/1505

Wollast, R., Boudrenghien, G., \& Linden, N. Van Der. (2018). Who Are the Doctoral Students Who Drop Out? Factors Associated with the Rate of Doctoral Degree Completion in Universities. 7(4). https://doi.org/10.5430/ijhe.v7n4p143

Yuniar, D., Mulyati, H., \& Cahyadi, E. (2019). Faktor-Faktor yang Memengaruhi Penyelesaian Masa Studi Program Pascasarjana di Institut Pertanian Bogor. Jurnal Akuntabilitas Manajemen Pendidikan, 7(2). https://doi.org/14-28. https://doi.org/10.21831/amp.v7i2.25084

York, T. T., Gibson, C., \& Rankin, S. (2015). Defining and Measuring Academic Success. Practical Assessment, Research, and Evaluation, 20(1), 5. https://doi.org/10.7275/hz5x-tx03 